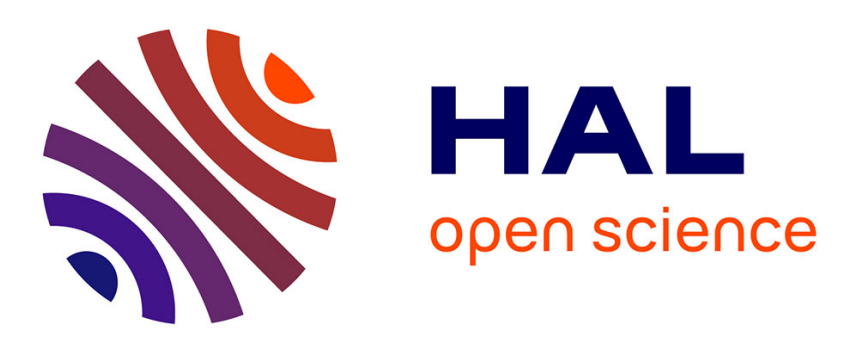

\title{
Anodic oxidation of p-phenylenediamines in battery grade electrolytes
}

\author{
E. Deunf, F. Dolhem, D. Guyomard, J. Simonet, P. Poizot
}

\section{To cite this version:}

E. Deunf, F. Dolhem, D. Guyomard, J. Simonet, P. Poizot. Anodic oxidation of pphenylenediamines in battery grade electrolytes. Electrochimica Acta, 2018, 262, pp.276-281. 10.1016/j.electacta.2018.01.010 . hal-01713511

HAL Id: hal-01713511

https://hal-univ-rennes1.archives-ouvertes.fr/hal-01713511

Submitted on 4 Apr 2018

HAL is a multi-disciplinary open access archive for the deposit and dissemination of scientific research documents, whether they are published or not. The documents may come from teaching and research institutions in France or abroad, or from public or private research centers.
L'archive ouverte pluridisciplinaire HAL, est destinée au dépôt et à la diffusion de documents scientifiques de niveau recherche, publiés ou non, émanant des établissements d'enseignement et de recherche français ou étrangers, des laboratoires publics ou privés. 


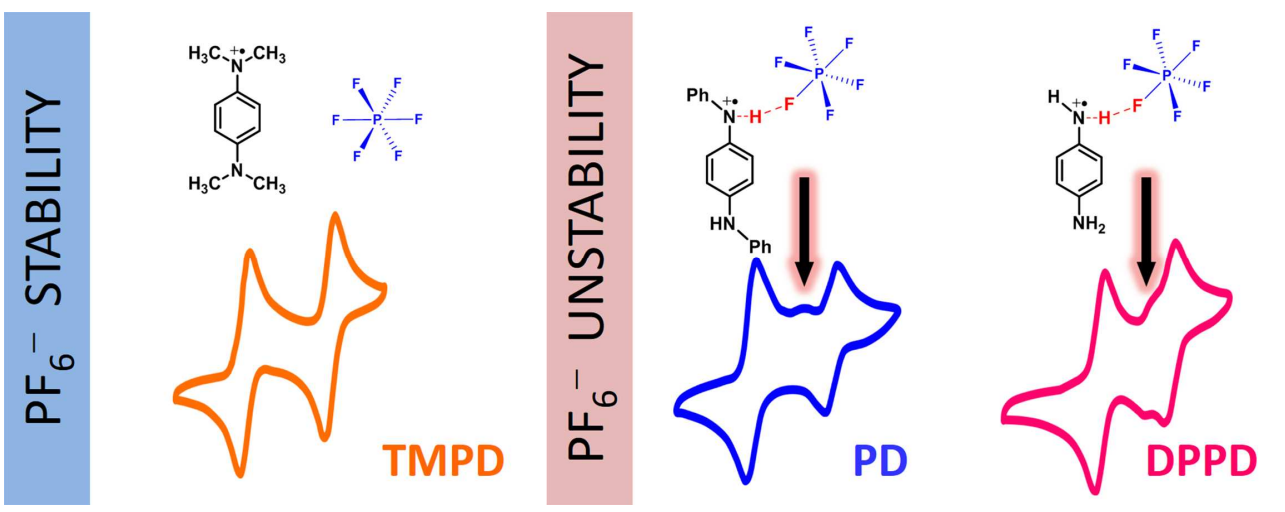




\title{
Anodic oxidation of $p$-phenylenediamines in battery grade
}

\section{electrolytes}

Elise Deunf ${ }^{\mathrm{a}}$, Franck Dolhem ${ }^{\mathrm{b}, \mathrm{c}}$, Dominique Guyomard ${ }^{\mathrm{a}}$, Jacques Simonet ${ }^{\mathrm{d}}$, Philippe Poizot ${ }^{\mathrm{a}, \mathrm{e}, *}$

${ }^{a}$ Institut des Matériaux Jean Rouxel (IMN), Université de Nantes, UMR CNRS 6502, 2 rue de la Houssinière, B.P. 32229, 44322 Nantes cedex 3, France.

${ }^{b}$ Laboratoire de Glycochimie, des Antimicrobiens et des Agroressources (LG2A), UMR CNRS 7378, Université de Picardie Jules Verne, 33 rue Saint-Leu, 80039 Amiens Cedex, France.

${ }^{c}$ Réseau sur le Stockage Électrochimique de l'Énergie (RS2E), FR CNRS 3459, France.

${ }^{d}$ Sciences Chimiques de Rennes (MaCSE), UMR CNRS 6226, Université de Rennes 1, Campus de Beaulieu, 35042 Rennes Cedex, France.

${ }^{e}$ Institut Universitaire de France (IUF), 1 rue Descartes, 75231 Paris Cedex 05, France.

\begin{abstract}
The use of anion-inserting organic electrode materials represent an interesting opportunity for developing 'metal-free' rechargeable batteries. Recently, crystallized conjugated diamines have emerged as new host materials able to accommodate anions upon oxidation at potentials higher than $3 \mathrm{~V}$ vs. $\mathrm{Li}^{+} / \mathrm{Li}^{0}$ in carbonate-based battery electrolytes. To further investigate the electrochemical behavior of such promising systems, comparison with electroanalytical data of soluble forms of conjugated diamines measured in battery grade electrolytes appeared quite useful. However, the literature on the topic is generally poor since such electrolyte media are not common in molecular electrochemistry. This contribution aims at providing relevant data on the characterization by cyclic voltammetry of unsubstituted, diphenyl-substituted and tetramethyl-substituted $p$-phenylenediamines. Basically, these three molecules revealed two reversible one-electron reaction upon oxidation corresponding to the electrogenerated radical cation and dication, respectively, combined with the association of electrolyte anions (i.e.,
\end{abstract}


$\mathrm{PF}_{6}^{-}, \mathrm{ClO}_{4}^{-}$and $\left.\mathrm{TfO}^{-}\right)$. The nature of the counter-anion did not show much influence on the electrochemical activity, which remained governed by the solvation process in high-polarity solvents (i.e., PC- or EC-based battery electrolytes). However, in presence of $\mathrm{PF}_{6}{ }^{-}$, the emergence of a pre-peak prior to the second oxidation step was observed when labile protons exist in the radical cation state. This contribution is attributed to a deprotonation reaction of the radical cation induced by the catalytic decomposition of $\mathrm{PF}_{6}^{-}$in presence of $\mathrm{H}^{+}$, which supports well the few other experimental data reported on the decomposition issues of $\mathrm{LiPF}_{6}$. In addition, substitution of the amine redox centers with appropriate functional groups (that increase the molecule $\pi$-delocalization) allowed to reach higher formal potentials without impacting the bi-electronic behavior and the reversibility of the processes.

Keywords: phenylenediamine, cyclic voltammetry, redox-active amine, organic batteries, $P F_{6}^{-}$ decomposition, lithium hexafluorophosphate

* Corresponding author at: Institut des Matériaux Jean Rouxel (IMN), Université de Nantes,

CNRS, 2 rue de la Houssinière, B.P. 32229, 44322 Nantes cedex 3, France.

E-mail address: philippe.poizot@cnrs-imn.fr 


\section{Introduction}

Global warming, fossil fuels depletion and rapid population growth are confronting our technology-oriented society with significant challenges notably in the field of power engineering. One of the priorities in this domain is to promote reliable, safe but also lowpolluting electrochemical storage devices for various practical applications from $\mathrm{mWh}$ to MWh range. Since the invention of the first rechargeable battery in 1859 by G. Planté (leadacid cell), the current manufacturing of batteries is still dominated by the use of redox-active inorganic species but the organic counterparts appear today as a promising alternative displaying several advantages such as low cost, environmental friendliness and the structural designability [1-9]. For instance, the operating redox potential of organic electrodes can be widely tuned by the choice of $(i)$ the electroactive functional group (both $n$ - or p-type ${ }^{1}[3,10]$ ), (ii) the molecular skeleton, and (iii) the substituent groups. Organic structures based on conjugated carbonyl/enolate redox-active moiety represent probably the most studied family of n-type organic electrode materials especially for developing $\mathrm{Li} / \mathrm{Na}$-based rechargeable systems. Conversely, p-type organic electrodes which involve an ionic compensation with anions [3,7,10] makes development of 'molecular' ion batteries possible [11] since numerous metal-free anions do exist. In this regard, our group has recently reported (for the first time) that crystallized conjugated diamines can accommodate anions at $E>3 \mathrm{~V} \mathrm{vs.} \mathrm{Li}^{+} / \mathrm{Li}^{0}$ in the solid state with an overall reversible two-electron reaction making them interesting for positive electrode applications [12-14].

In light of the opportunity offer by this new family of insertion compounds and to go further in the understanding of electrochemical processes, we revisited the anodic oxidation of $p$ phenylenediamine derivatives by cyclic voltammetry but measured in typical (aprotic) battery grade electrolytes for which less than 0.1 ppm of both $\mathrm{O}_{2}$ and $\mathrm{H}_{2} \mathrm{O}$ are guaranteed. More specifically, we report herein the electrochemical feature of three selected phenylenediamines

\footnotetext{
${ }^{1}$ Note that n-type structures involve upon oxidation an ionic compensation with cation release whereas p-type structures imply an anion.
} 
(i.e., $N, N^{\prime}$-p-phenylenediamine, PD; $N, N^{\prime}$-diphenyl-p-phenylenediamine, DPPD; $N, N, N^{\prime}, N^{\prime}$ tetramethyl-p-phenylenediamine, TMPD-Figure 1a) solubilized at millimolar concentrations in different electrolyte formulations including $\mathrm{LiPF}_{6}$ as the most popular supporting salt used in the Li-ion battery by manufacturers and researchers.

\section{Experimental}

\subsection{Chemicals}

The different electrolyte formulations were prepared in an Ar-filled glovebox (MBRAUN) containing less than $0.1 \mathrm{ppm}$ of both $\mathrm{O}_{2}$ and $\mathrm{H}_{2} \mathrm{O}$ from lithium perchlorate $\left(\mathrm{LiClO}_{4}\right)$, lithium hexafluorophosphate $\left(\mathrm{LiPF}_{6}\right)$, propylene carbonate $(\mathrm{PC})$, ethylene carbonate $(\mathrm{EC})$ and dimethylcarbonate (DMC) purchased from BASF (battery grade) and used as received. Lithium trifluoromethanesulfonate (LiOTf, 99.995\%, Aldrich) was dried at $100^{\circ} \mathrm{C}$ under vacuum for $15 \mathrm{~h}$ prior use. The common "LP30" battery grade electrolyte (i.e., LiPF $1 \mathrm{M}$ in EC:DMC 1:1 vol./vol.) was directly employed as received from Novolyte. Amines was purchased from Aldrich with the following purities: $N, N^{\prime}$-p $p$-phenylenediamine PD (99\%), $N, N, N^{\prime}, N^{\prime}$-tetramethyl-p-phenylenediamine TMPD $(\geq 97 \%), N, N^{\prime}$-diphenyl- $p$ phenylenediamine DPPD (98\%), and triethylamine ( $\left.\mathrm{Et}_{3} \mathrm{~N}, \geq 99 \%\right)$.

\subsection{Electrochemical procedures}

Cyclic voltammetric (CV) experiments were recorded on a SP-150 potentiostat/galvanostat (Bio-Logic S.A., Claix, France). All electrochemical experiments were systematically conducted from freshly prepared electrolyte solutions (except the "LP30" battery grade electrolyte, Novolyte $)$ in a conventional three-electrode setup $(\mathrm{V}=10 \mathrm{~mL})$ placed inside an Ar-filled glovebox (MBRAUN) containing less than $0.1 \mathrm{ppm}$ of both $\mathrm{O}_{2}$ and $\mathrm{H}_{2} \mathrm{O}$. The working electrode was constituted of a commercial platinum disk microelectrode with a diameter of $1.6 \mathrm{~mm}$ (ALS Japan). Facing the working electrode, a large platinum wire was 


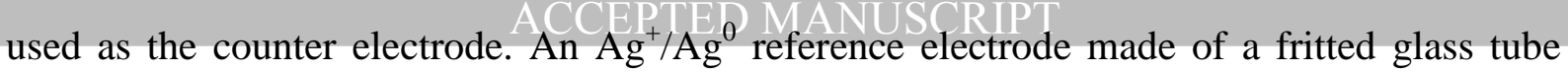
filled with an $\mathrm{AgNO}_{3} 10 \mathrm{mM}$ solution in acetonitrile [15] was systematically used. However, reported potentials were also given against the $\mathrm{Li}^{+} / \mathrm{Li}^{0}$ reference electrode for a better appreciation of the battery community. This second reference electrode, made of lithium metallic attached on a $\mathrm{Pt}$ wire, was experimentally checked versus the $\mathrm{Ag}^{+} / \mathrm{Ag}^{0}$ reference electrode in each studied electrolyte giving a correction of the measured potentials of $+3.6 \mathrm{~V}$.

\section{Results and discussion}

The typical electrochemical activity of the simple PD molecule is preliminary reported being a representative member of this family of redox-active compounds. In addition, $\mathrm{PC} / \mathrm{LiClO}_{4}$

$1 \mathrm{M}$ electrolyte was first employed in order to be aligned with our former battery cycling tests performed on crystallized $p$-phenylenediamines derivatives $[12,13]$. Basically, the oxidation of PD in such an electrolyte shows two anodic peaks (I, II) located at 3.58 and $4.07 \mathrm{~V}$ vs. $\mathrm{Li}^{+} / \mathrm{Li}^{0}$, respectively (Figure $1 b$ ). When reversing the scan, two corresponding cathodic peaks are observed. The peak-to-peak separation values for both steps (I/I', II/II') are equal to 60 $\mathrm{mV}$, which indicates the occurrence of two fully reversible one-electron processes. The anodic events are assigned to the electrogeneration of the radical cation $\mathbf{P D}^{\bullet+}$ at peak I further followed by the dicationic form $\left(\mathbf{P D}^{2+}\right)$ at peak II. The ratio between the peak currents and the square root of the scan rate at both anodic and cathodic waves shows linearity (Figure 1c), which confirms the two electrochemical processes are under diffusion control as expected for reversible systems $[15,16]$.

At this point it should be recalled that the typical mechanisms for the electrochemical oxidation of phenylenediamines have already been established in common aprotic solvents for molecular electrochemistry [17-21] and very recently in the battery grade PC/LiBF $41 \mathrm{M}$ electrolyte for non-aqueous redox flow batteries [22]. Their oxidation processes through this 
two reversible one-electron transfer with the formation of successive stable radical cation and dication species. However, in the case of primary and secondary amines - meaning the existence of labile protons - this behavior can be impacted by the presence of acid-base species in the electrolyte [20,21]. Indeed, these labile protons are easily involved in an acidbase reaction competing with the electrochemical process, sometimes even leading to the loss of the reversible character. Interestingly, in $\mathrm{PC} \mathrm{LiClO}_{4} 1 \mathrm{M}$ electrolyte one can observe that $\mathbf{P D}^{\bullet+}$ remains stable on the voltammetry time-scale and can undergo a second electrochemical oxidation at higher potentials for producing $\mathbf{P D}^{2+}$. Similarly, this dicationic form is also stable enough towards chemical side-reactions and is reduced back on the reverse scan. For comparison, two other common lithiated salts used in Li-batteries $\left(\mathrm{LiPF}_{6}\right.$ and LiOTf) were also evaluated as supporting electrolytes using again PC as the solvent. The resulting CV curves of PD shows quite similar electrochemical steps (Figure 2a) with fully reversible peaks obtained at anodic potentials of 3.6 and $4.1 \mathrm{Vvs} . \mathrm{Li}^{+} / \mathrm{Li}^{0}$, respectively. This result attests that neither the thermodynamic nor the kinetic of the stepwise one-electron oxidation reactions are impacted by the counter anions of the supporting electrolyte although exhibiting very different donor number (DN) in PC and van der Waals volume [23-25]. These results are in agreement with a dominance of the solvation process in high polarity aprotic solvents such as PC $\left(\varepsilon_{\mathrm{r}} \sim 66\right)$ in which a low ion-pairing is expected [26]. However, the use of $\mathrm{LiPF}_{6}$ supporting salt shows some slight differences with the appearance of a new contribution between the two regular steps and a peak-to-peak separation of the second anodic wave shifted from reversibility $\left(\Delta E_{1 / 2}=90 \mathrm{mV}\right)$ suggesting a quasi-reversible process. When excluding $\mathrm{LiPF}_{6}$, the solvent change does not affect the reversibility of the two electrochemical steps involved with PD. Figure $2 \mathrm{~b}$ shows for instance a comparison of CVs recorded in PC, DMC and EC-DMC, respectively, using a concentration of 1 mol.L $\mathrm{L}^{-1}$ of $\mathrm{LiClO}_{4}$. 
Diphenyl-substituted (DPPD) and tetramethyl-substituted $p$-phenylenediamines (TMPD)

were also selected as representative secondary and tertiary $p$-phenylenediamine derivatives of interest for this comparative study. In fact, the possible $\pi$-delocalization by mesomeric effect (+M) occurring with the DPPD structure should induce both a positive potential shift and higher acidic character of the secondary amine functional group. On the contrary, methyl substituent groups which are electron-donating by inductive effect $(+\mathrm{I})$ would decrease the oxidative strength of the $p$-phenylenediamine backbone (lower formal potential) whereas no acidic protons do exist. Figure 3 summarizes the most striking features observed in both PC/LiClO $41 \mathrm{M}$ and EC-DMC/LiPF $61 \mathrm{M}$ electrolytes. As expected with DPPD, the reversible stepwise one-electron oxidation steps occur at 140 and $50 \mathrm{mV}$ higher than the corresponding events observed with PD while TMPD shows the lowest redox potentials of the series. It is worth noting that the presence of substituent groups on the $p$-phenylenediamine backbone does not impact the reversibility of the processes and further illustrates the stability of both the neutral and the electrogenerated species. Table 1 shows the diffusion coefficient values experimentally determined from the voltammetric curves recorded at different scan rates $\left(50 \mathrm{mV} . \mathrm{s}^{-1}\right.$ to $\left.10 \mathrm{~V} . \mathrm{s}^{-1}\right)$. These values are comparable to those reported in the literature $[22,23]$. The peculiar electrochemical feature previously observed with $\mathbf{P D}$ in presence of $\mathrm{PF}_{6}{ }^{-}$ anion (Figure 2a) is again noticed in the case of DPPD with the appearance this time of an obvious reversible pre-peak (III) prior to the second main electrochemical step (Figure 3). One possible explanation could be related to the peculiar chemistry of $\mathrm{LiPF}_{6}$ in high polarity aprotic solvents (denoted :S). Indeed, it has long been known in the field of Li-ion batteries [25,28-31] that undissociated $\mathrm{LiPF}_{6}$ do exist at relatively high electrolyte concentrations (in the range of $1 \mathrm{~mol} . \mathrm{L}^{-1}$ ) in equilibrium with $\mathrm{F}^{-}$and the strong Lewis acid, $\mathrm{PF}_{5}$ :

$$
\left[\mathrm{Li}^{+} \mathrm{PF}_{6}^{-}\right]_{(\text {ion pair })}+: \mathbf{S} \rightleftharpoons\left[\mathbf{S}: \mathrm{PF}_{5}\right]_{(\text {sol })}^{+}+\mathrm{LiF}
$$


The dilemma is that in high polarity aprotic solvents the dissociation of $\left[\mathrm{Li}^{+} \mathrm{PF}_{6}^{-}\right]$ion pairs is facilitated but the stabilization of $\mathrm{PF}_{5}$ too. In addition, it has been shown that the presence of $\mathrm{H}^{+}$ion in the medium that also form ion pairs with $\mathrm{PF}_{6}{ }^{-}$catalyzes its decomposition according to the following equilibria due to the strong $\mathrm{H}^{\cdots} \mathrm{F}$ interactions [30]:

$$
\mathrm{H}^{+}+\mathrm{PF}_{6(\text { sol })}^{-} \rightleftharpoons\left[\mathrm{H}^{+} \mathrm{PF}_{6}^{-}\right]_{(\text {ion pair })} \rightleftharpoons \mathrm{H}^{\cdots} \mathrm{F}-\mathrm{PF}_{5} \rightleftharpoons \mathrm{HF}+\mathrm{PF}_{5}
$$

In the case of PD and DPPD, the resulting radical cations electrogenerated at peak I exhibit more polarized $\mathrm{N}-\mathrm{H}$ bonds in comparison with the pristine state. In the presence of $\mathrm{PF}_{6}^{-}$(and potentially $\mathrm{F}^{-}$in the vicinity of the electrode), the acidic proton can be neutralized according to Eq. 2 for producing the corresponding radical, which is a more readily oxidizable species. This hypothesis is further supported by the fact that no pre-peak is observed with TMPD for which no labile protons do exist. However, supplementary experiments were also conducted by adding a base to $\mathrm{LiPF}_{6}$-free electrolyte media in order to verify the deprotonation assumption. In practice, triethylamine $\left(\mathrm{Et}_{3} \mathrm{~N}\right)$ was used as a common base in organic chemistry. Figure 4 summarizes the as-obtained results by selecting both DPPD and TMPD as the two representative cases bearing no labile proton. As expected, in the presence of trimethylamine $(0.5 \mathrm{mM})$, the pre-peak appeared with DPPD (III) while the electrochemical behavior of TMPD was not affected. Note that a pre-peak (IV) was also observed prior to the first oxidation step (I), which can be attributed to the deprotonation reaction of DPPD itself at this concentration of base. The proposed overall mechanism is finally depicted in Figure 5 in the presence of $\mathrm{PF}_{6}^{-}$or by adding $\mathrm{Et}_{3} \mathrm{~N}^{-}$in $\mathrm{PF}_{6}{ }^{-}$-free electrolyte. Interestingly, this particular electrochemical investigation focused on both substituted and unsubstituted $p$ phenylenediamines supports well the few other reports pointed out the decomposition issues of $\mathrm{LiPF}_{6}$ in aprotic media when labile protons are present. 


\section{Conclusions}

This study aimed at emphasizing the potentiality of $p$-phenylenediamines which can offer high potential and multi-electronic behavior as p-type materials for battery applications. A specific cyclic voltammetry study was then conducted to evaluate the electrochemical behavior of three selected $p$-phenylenediamines derivatives (PD, DPPD and TMPD) dissolved in several battery grade (carbonate) electrolyte media. Among the various electrolytes tested, it appeared a chemical instability of the electrogenerated radical cation in presence of $\mathrm{LiPF}_{6}$ when labile protons do exist on nitrogen atoms due to the propensity of $\mathrm{PF}_{6}^{-}$to be decomposed in high-polarity solvents such as PC- or EC-based battery electrolytes; this phenomenon being catalyzed by labile protons. This electrochemical study provides also to the Li battery community a supplementary proof concerning the high reactivity of the most popular supporting salt versus any labile proton potentially present in a battery electrolyte.

\section{Acknowledgments}

This work was partially funded by a public grant overseen by the French National Research Agency as part of the program "Investissements d'Avenir" [grant number ANR-13-PRGE0012] also labeled by the Pôle de Compétitivité S2E2. 


\section{References}

[1] P. Poizot, F. Dolhem, Clean energy new deal for a sustainable world: from non-CO $\mathrm{CO}_{2}$ generating energy sources to greener electrochemical storage devices, Energy Environ. Sci. 4 (2011) 2003-2019.

[2] Y. Liang, Z. Tao, J. Chen, Organic electrode materials for rechargeable lithium batteries, Adv. Energy Mater. 2 (2012) 742-769.

[3] Z. Song, H. Zhou, Towards sustainable and versatile energy storage devices: an overview of organic electrode materials, Energy Environ. Sci. 6 (2013) 2280-2301.

[4] B. Haeupler, A. Wild, U.S. Schubert, Carbonyls: Powerful organic materials for secondary batteries, Adv. Energy Mater. 5 (2015) 1402034.

[5] Q. Zhao, C. Guo, Y. Lu, L. Liu, J. Liang, J. Chen, Rechargeable lithium batteries with electrodes of small organic carbonyl salts and advanced electrolytes, Ind. Eng. Chem. Res. 55 (2016) 5795-5804.

[6] T. B. Schon, B. T. McAllister, P.-F. Li, D. S. Seferos, The rise of organic electrode materials for energy storage, Chem. Soc. Rev. 45 (2016) 6345-6404.

[7] S. Muench, A. Wild, C. Friebe, B. Häupler, T. Janoschka, U.S. Schubert, Polymer-based organic batteries, Chem. Rev. 116 (2016) 9438-9484.

[8] Q. Zhao, Y. Lu, J. Chen, Advanced organic electrode materials for rechargeable sodiumion batteries, Adv. Energy Mater. 7 (2017) 1601792.

[9] J. Winsberg, T. Hagemann, T. Janoschka, M.D. Hager, U.S. Schubert, Redox-flow batteries: from metals to organic redox-active materials, Angew. Chem. Int. Ed. 56 (2016) 686-711.

[10] S. Gottis, A.-L. Barrès, F. Dolhem, P. Poizot, Voltage gain in lithiated enolate-based organic cathode materials by isomeric effect, ACS Appl. Mater. Interfaces. 6 (2014) 10870-10876. 
[11] M. Yao, H. Sano, H. Ando, T. Kiyobayashi, Molecular ion battery: a rechargeable system without using any elemental ions as a charge carrier, Sci. Rep. 5 (2015) 10962.

[12] E. Deunf, P. Moreau, E. Quarez, D. Guyomard, F. Dolhem, P. Poizot, Reversible anion intercalation in a layered aromatic amine: A High-voltage host structure for organic batteries, J. Mater. Chem. A. 4 (2016) 6131-6139.

[13] E. Deunf, N. Dupré, E. Quarez, P. Soudan, D. Guyomard, F. Dolhem, P. Poizot, Solvation, exchange and electrochemical intercalation properties of disodium 2,5(dianilino)terephthalate, CrystEngComm. 18 (2016) 6076-6082.

[14] E. Deunf, P. Jiménez, D. Guyomard, F. Dolhem, P. Poizot, A dual-ion battery using diamino-rubicene as anion-inserting positive electrode material, Electrochem. Commun. 72 (2016) 64-68.

[15] A.J. Bard, L.R. Faulkner, Electrochemical Methods: Fundamentals and Applications, second edition, John Wiley \& Sons, Inc., U.K., 2001.

[16] C. Batchelor-McAuley, R.G. Compton, Voltammetry of multi-electron electrode processes of organic species, J. Electroanal. Chem. 669 (2012) 73-81.

[17] M. Opałło, The solvent effect on the electro-oxidation of 1,4-phenylenediamine. The influence of the solvent reorientation dynamics on the one-electron transfer rate, J. Chem. Soc., Faraday Trans. 1. 82 (1986) 339-347.

[18] A. Bewick, D. Serve, T.A. Joslin, Anodic oxidation of aromatic nitrogen compounds: Spectroelectrochemical studies of EE and EECr processes with a coupled redox reaction, J. Electroanal. Chem. Interfacial Electrochem. 154 (1983) 81-105.

[19] H. Fernández, M.A. Zón, Determination of the kinetic and activation parameters for the electro-oxidation of $N, N, N^{\prime}, N^{\prime}$-tetramethyl-p-phenylenediamine (TMPD) in acetonitrile (ACN) by chronocoulometry and other electrochemical techniques, J. Electroanal. Chem. Interfacial Electrochem. 283 (1990) 251-270. 
[20] H. de Santana, S. Quillard, E. Fayad, G. Louarn, In situ UV-vis and Raman spectroscopic studies of the electrochemical behavior of $N, N^{\prime}$-diphenyl-1,4phenylenediamine, Synth. Met. 156 (2006) 81-85.

[21] A. Maleki, D. Nematollahi, Mechanism diversity in anodic oxidation of $N, N$-dimethyl- $p$ phenylenediamine by varying pH, J. Electroanal. Chem. 704 (2013) 75-79.

[22] H.-S. Kim, K.-J. Lee, Y.-K. Han, J.H. Ryu, S.M. Oh, A comparative study on the solubility and stability of pphenylenediamine-based organic redox couples for nonaqueous flow batteries, J. Power Sources 348 (2017) 264-269.

[23] M. Ue, Mobility and ionic association of lithium and quaternary ammonium salts in propylene carbonate and $\gamma$-butyrolactone, J. Electrochem. Soc. 141 (1994) 3336-3342.

[24] M. Ue, Ionic radius of $\left(\mathrm{CF}_{3} \mathrm{SO}_{2}\right)_{3} \mathrm{C}$ and applicability of stokes law to its propylene carbonate solution. J. Electrochem. Soc. 143 (1996) L270-L271.

[25] W. Linert, A. Camard, M. Armand, C. Michot, Anions of low Lewis basicity for ionic solid state electrolytes, Coord. Chem. Rev. 226 (2002) 137-141.

[26] F. Barrière, W.E. Geiger, Use of weakly coordinating anions to develop an integrated approach to the tuning of $\Delta E_{1 / 2}$ values by medium effects, J. Am. Chem. Soc. 128 (2006) $3980-3989$.

[27] R. G. Evans, O. Klymenko, C. Hardacre, K. R.Seddon, R. Compton, Oxidation of $N, N, N^{\prime}, N^{\prime}$-tetraalkyl-para-phenylenediamines in a series of room temperature ionic liquids incorporating the bis(trifluoromethylsulfonyl)imide anion, J. Electroanal. Chem. 556 (2003) 179-188.

[28] S.E. Sloop, J.K. Pugh, S. Wang, J.B. Kerr, K. Kinoshita, Chemical reactivity of $\mathrm{PF}_{5}$ and $\mathrm{LiPF}_{6}$ in ethylene carbonate/dimethyl carbonate solutions. Electrochem. Solid-State Lett. 4 (2001) A42-A44.

[29] K. Tasaki, K. Kanda, S. Nakamura, M. Ue, Decomposition of $\mathrm{LiPF}_{6}$ and stability of $\mathrm{PF}_{5}$ in Li-ion battery electrolytes. J. Electrochem. Soc. 150 (2003) A1628-A1636. 
[30] C.L. Campion, W. Li, B.L. Lucht, Thermal decomposition of LiPF 6 -based electrolytes for Lithium-ion batteries. J. Electrochem. Soc. 152 (2005) A2327-A2334.

[31] A.V. Plakhotnyk, L. Ernst, R. Schmutzler, Hydrolysis in the system LiPF carbonate-dimethyl carbonate- $\mathrm{H}_{2} \mathrm{O}$. J. Fluorine Chem. 126 (2005) 27-31. 
<smiles>Nc1ccc(N)cc1</smiles><smiles>c1ccc(Nc2ccc(Nc3ccccc3)cc2)cc1</smiles>

PD

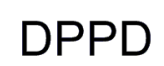

\section{Potential vs. (Li/Li') / V}
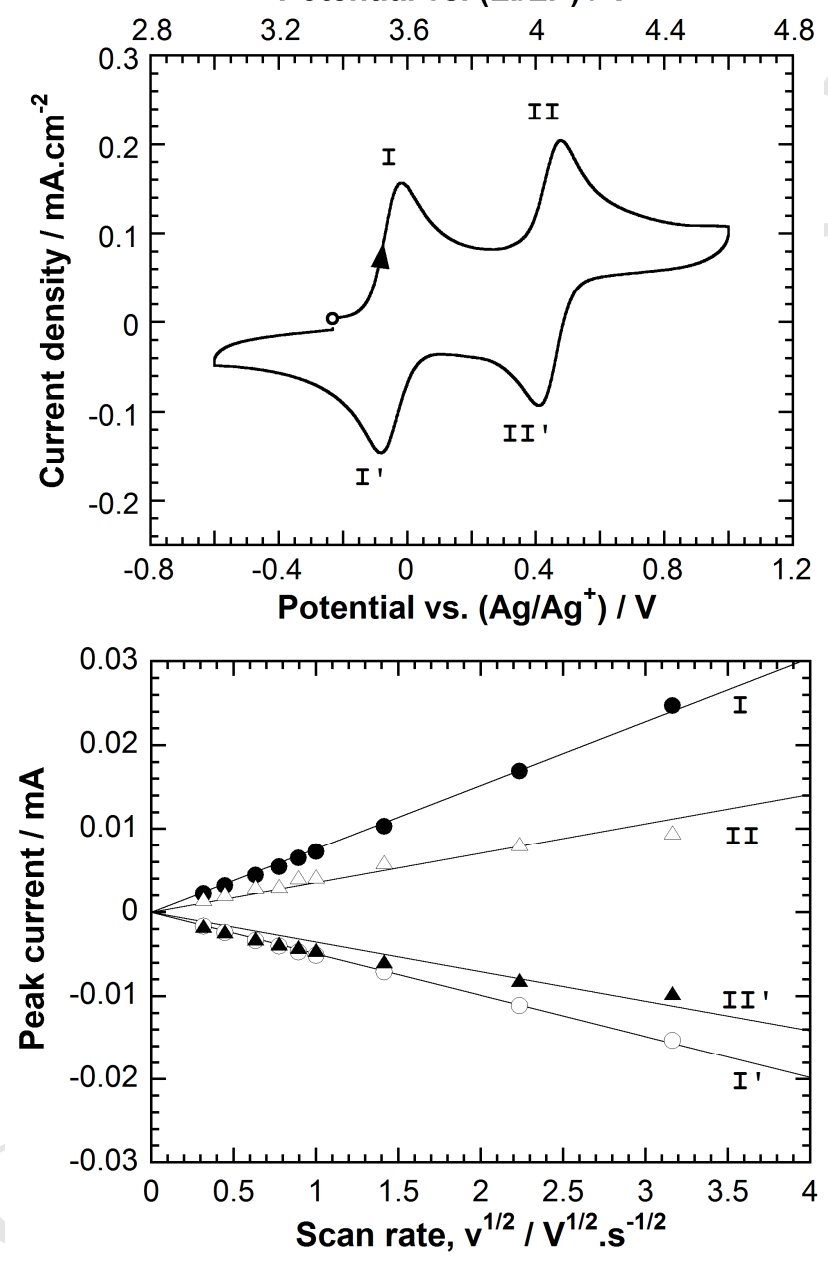

Figure 1. (a) Structural formula of studied $p$-phenylenediamines denoted PD, DPPD and TMPD, respectively. (b) Typical cyclic voltammogram of $\mathbf{P D}$ measured at a concentration of $1 \mathrm{mM}$ in $\mathrm{PC} \mathrm{LiClO}_{4} 1 \mathrm{M}$ recorded on Pt disk microelectrode at a scan rate of $200 \mathrm{mV} . \mathrm{s}^{-1}$. (c) Plotting of the peak currents against the square root of the scan rate (from $100 \mathrm{mV} . \mathrm{s}^{-1}$ to $\left.10 \mathrm{~V} \cdot \mathrm{s}^{-1}\right)$ 
a) PD - varying the counter-anion in PC:

Potential vs. $\left(\mathrm{Li}^{\mathrm{L}} \mathrm{Li}^{+}\right) / \mathrm{V}$

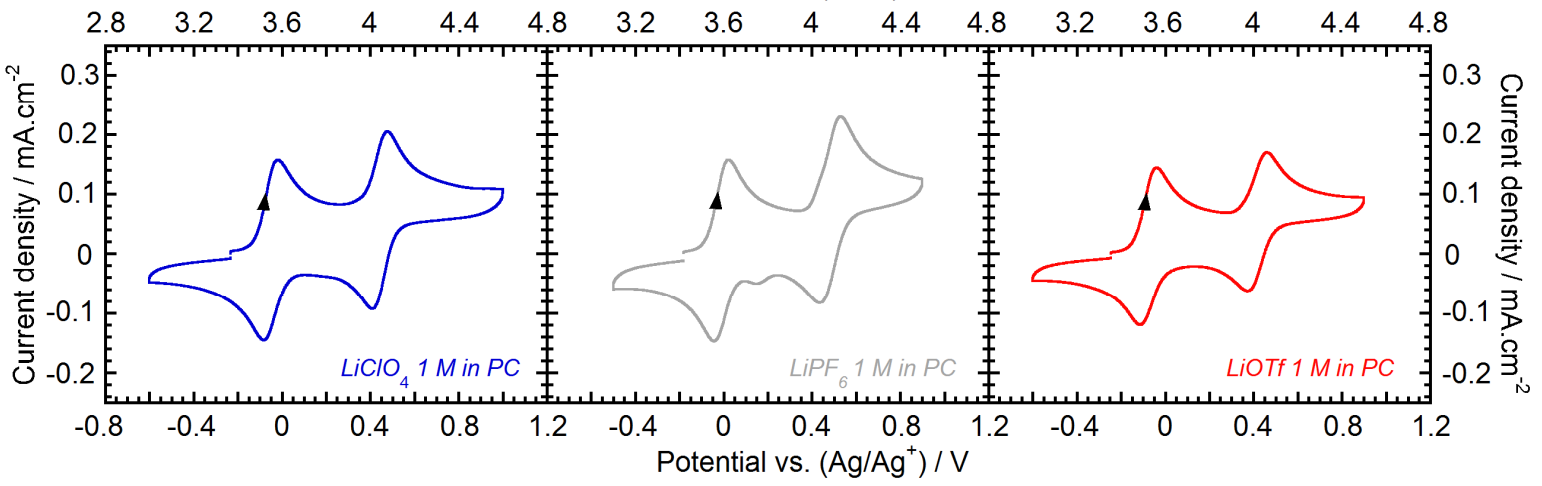

b) PD - varying the solvent keeping $\mathrm{LiClO}_{4}$ as the supporting salt:

Potential vs. $\left(\mathrm{Li}^{\mathrm{L}} \mathrm{Li}^{+}\right) / \mathrm{V}$

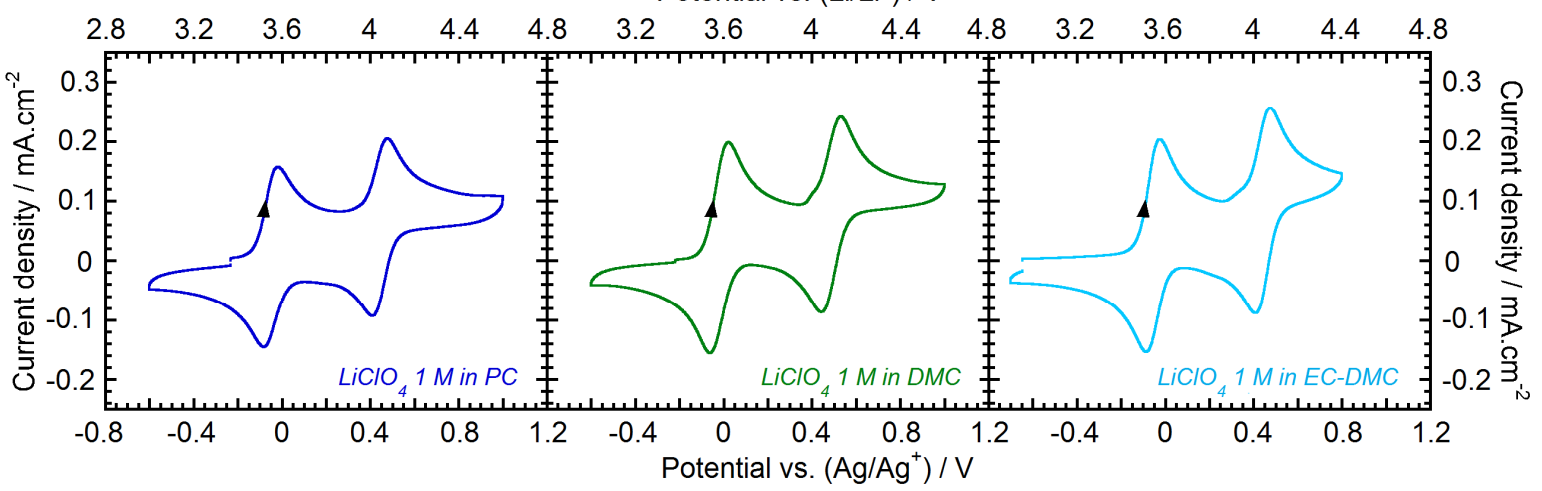

Figure 2. (a) Comparison of typical CV curves of PD in recorded on Pt disk microelectrode at a scan rate of $200 \mathrm{mV} . \mathrm{s}^{-1}$ using a concentration of $1 \mathrm{mM}$ in $\mathrm{PC} / \mathrm{LiClO}_{4} 1 \mathrm{M}, \mathrm{PC} / \mathrm{LiPF}_{6} 1 \mathrm{M}$, and PC/LiOTf $1 \mathrm{M}$, respectively. (b) Comparison of typical CV curves of PD recorded on Pt

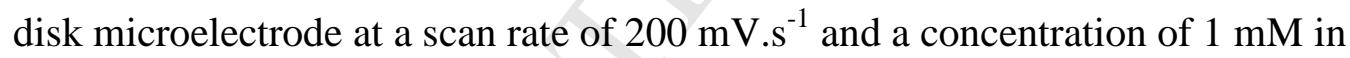
$\mathrm{PC} / \mathrm{LiClO}_{4} 1 \mathrm{M}, \mathrm{DMC} / \mathrm{LiClO}_{4} 1 \mathrm{M}$, and EC-DMC/LiClO $41 \mathrm{M}$, respectively. 


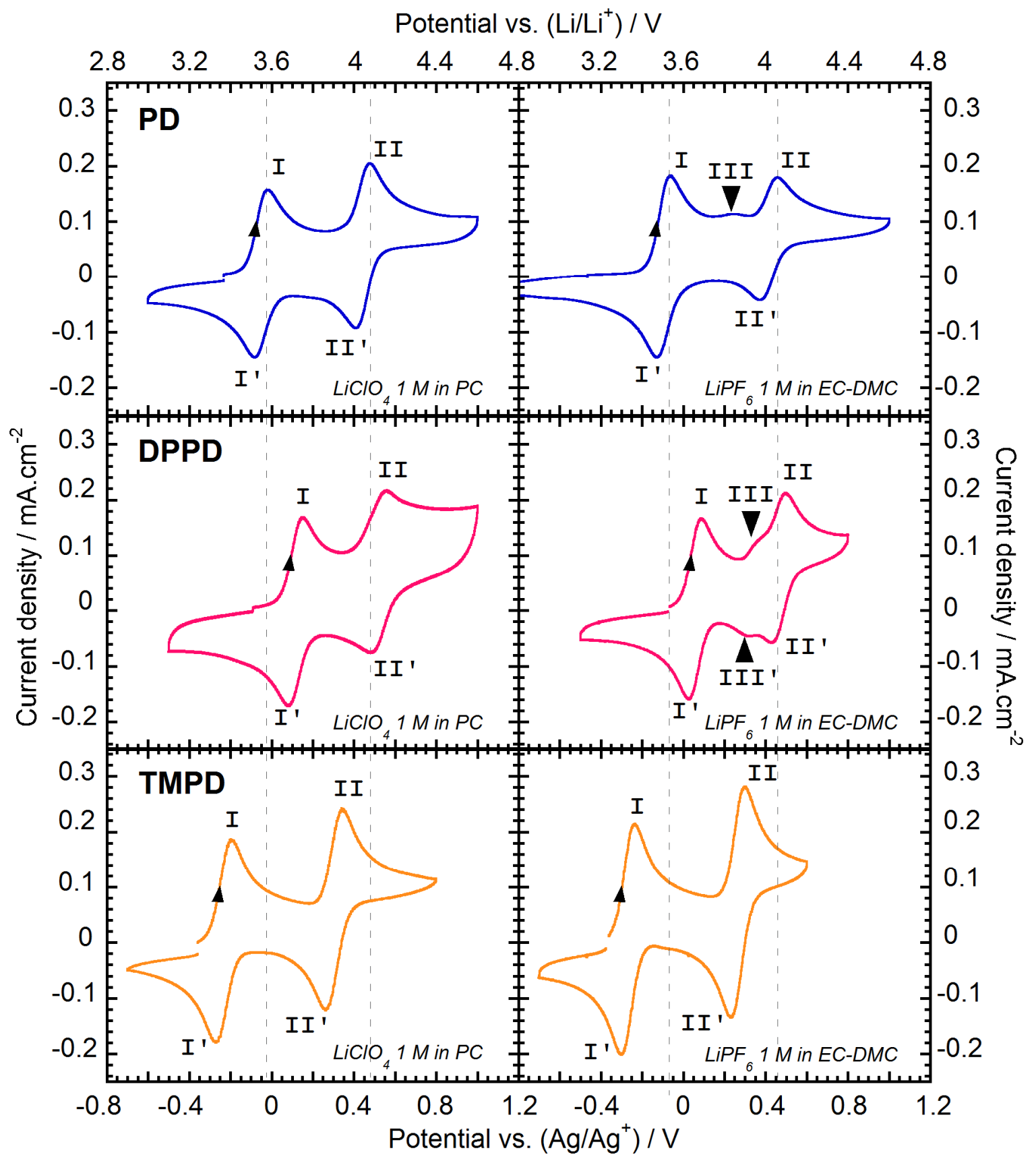

Figure 3. Comparison of typical CV curves recorded on Pt disk microelectrode at a scan rate of $200 \mathrm{mV} . \mathrm{s}^{-1}$ using a concentration of $1 \mathrm{mM} \mathrm{PC} / \mathrm{LiClO}_{4} 1 \mathrm{M}$ or EC-DMC/LiPF $61 \mathrm{M}$ electrolyte. Note that dotted lines have been added to highlight the potential shifts of the two main electrochemical steps observed with DPPD and TMPD compared to PD. 
(a)

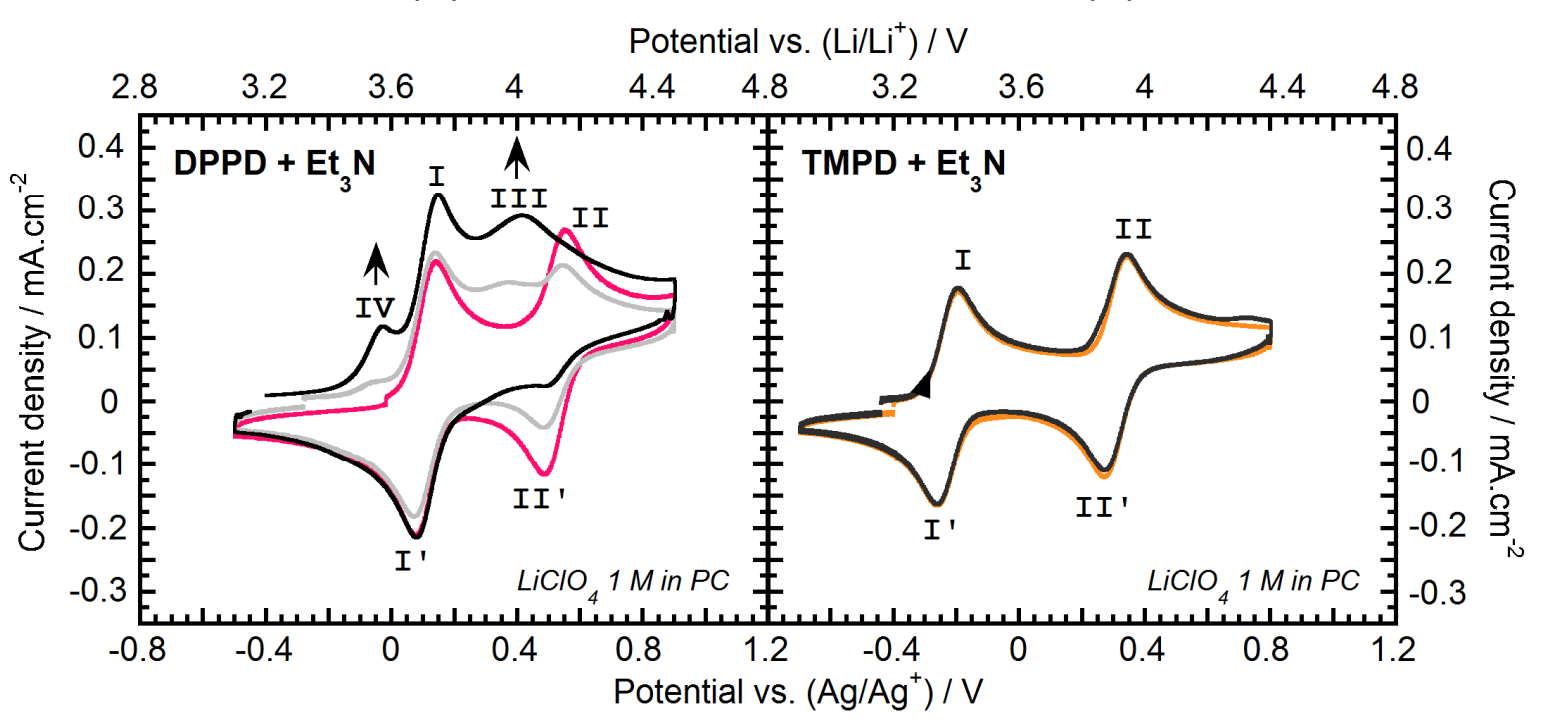

Figure 4. Typical CV curves recorded on Pt disk microelectrode at a scan rate of $200 \mathrm{mV} . \mathrm{s}^{-1}$ in $\mathrm{PC} / \mathrm{LiClO}_{4} 1 \mathrm{M}$ electrolyte for : (a) DPPD at a concentration of $1 \mathrm{mM}$ in absence (pink) and presence of $0.5 \mathrm{mM}$ (grey) and $1 \mathrm{mM}$ (black) of triethylamine, (b) TMPD at a concentration of $1 \mathrm{mM}$ in absence (orange) and presence of $1 \mathrm{mM}$ (black) of triethylamine. 

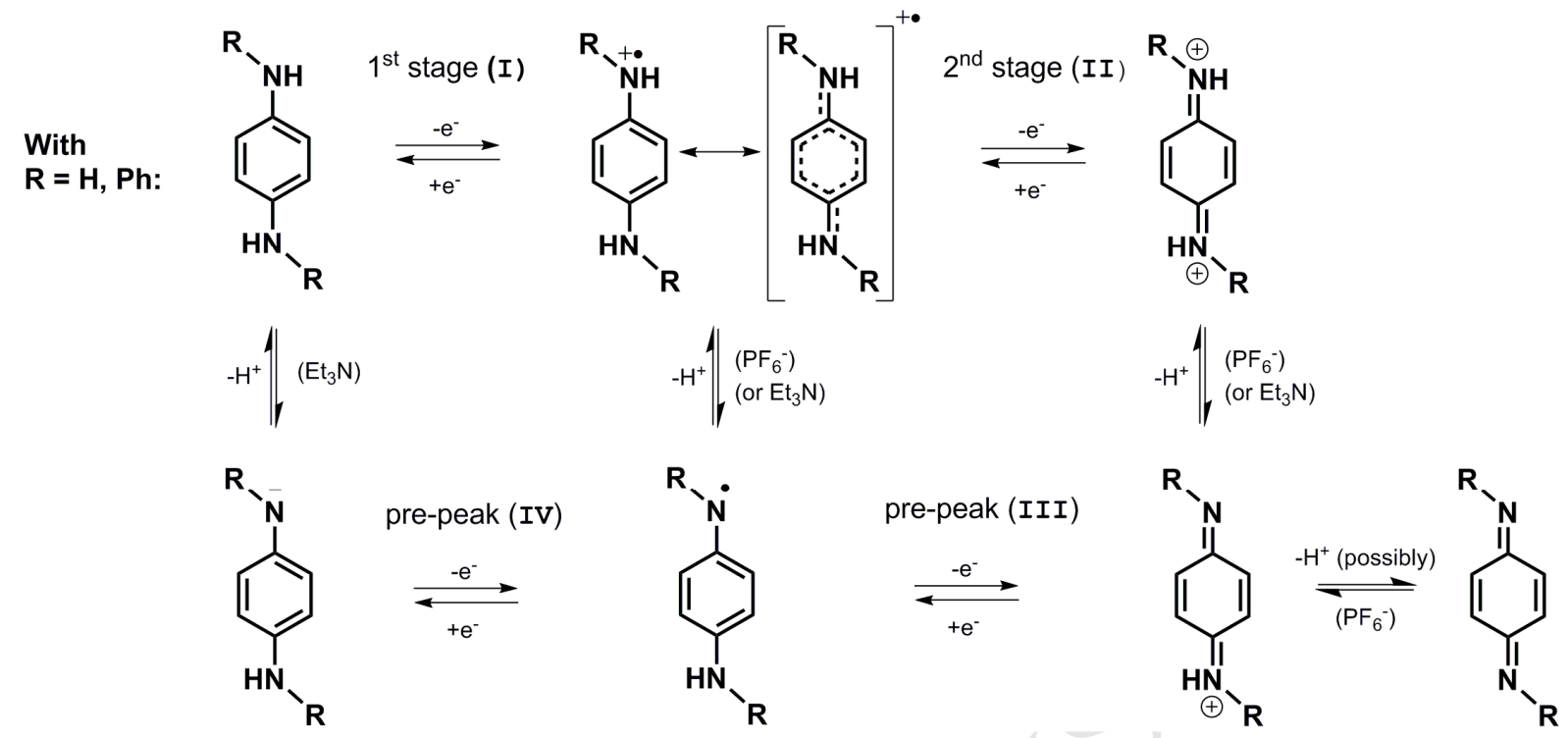

Figure 5. Proposal for explaining the peculiar electrochemical behavior of PD and DPPD in presence of $\mathrm{LiPF}_{6}$ in the electrolyte. 


\begin{tabular}{cccc} 
Electrolyte & $D_{\mathbf{P D}}\left(\mathrm{cm}^{2} \mathrm{~s}^{-1}\right)$ & $D_{\text {DPPD }}\left(\mathrm{cm}^{2} \mathrm{~s}^{-1}\right)$ & $D_{\text {TMPD }}\left(\mathrm{cm}^{2} \mathrm{~s}^{-1}\right)$ \\
\hline $\mathrm{PC} / \mathrm{LiClO}_{4} 1 \mathrm{M}$ & $1.9810^{-6}$ & $0.3410^{-6}$ & $4.9010^{-6}$ \\
$\mathrm{EC}-\mathrm{DMC} / \mathrm{LiClO}_{4} 1 \mathrm{M}$ & $1.7410^{-6}$ & $0,1910^{-6}$ & $3.4010^{-6}$
\end{tabular}

Table 1. Diffusion coefficients for the oxidation of phenylenediamines in the different electrolytes calculated with the Randles-Sevcik equation from the slope of the experimental curves $i_{\mathrm{p}}=f\left(\mathrm{v}^{1 / 2}\right)$. 